Article

\title{
Application of Wastewater Reuse with Photocatalyst Prepared by Sol-Gel Method and Its Kinetics on the Decomposition of Low Molecular Weight Pollutants
}

\author{
Jinwook Chung ${ }^{1}$, Seungjoon Chung ${ }^{1}$, Gyuyoung Lee ${ }^{1,2}$ and Yong-Woo Lee ${ }^{2, *}$ \\ 1 R\&D Center, Samsung Engineering Co. Ltd., 41 Maeyoung-Ro, 269 Beon-Gil, Youngtong-Gu, Suwon, \\ Gyeonggi-Do 16523, Korea; chung.j@samsung.com (J.C.); phd.chung@samsung.com (S.C.); \\ young8.lee@samsung.com (G.L.) \\ 2 Department of Chemical and Molecular Engineering, Hanyang University, 55 Hanyangdaehakro, \\ Sangrok-Gu, Ansan, Gyeonggi-Do 15588, Korea \\ * Correspondence: yongwoolee@hanyang.ac.kr; Tel.: +82-31-400-5508; Fax: +82-31-400-5457
}

Received: 21 May 2020; Accepted: 11 June 2020; Published: 12 June 2020

\begin{abstract}
The development of immobilized photocatalyst as a strategy for problematic electronics wastewater reuse is described in this study. The strategy was to perform separate rinsing, mostly consisting of low molecular weight compounds, and to decompose them with a simple process, based on the advanced oxidation process (AOP). Extensive studies were performed on the preparation conditions of immobilized photocatalysts by sol-gel method under various amount of precursor and support, water to precursor ratio, $\mathrm{pH}$, aging time, and calcination conditions. The optimized preparation conditions were chosen by measuring removal efficiencies of isopropyl alcohol as a representative target compound with supportive SEM and XRD analyses. Removal efficiencies with photocatalyst and UV irradiation in synthetic wastewater simulating electronics wastewater were evaluated over time. Removal efficiencies of alcohol, acetone, ethanol, and acetaldehyde reached $97.2 \%, 71.2 \%, 99.0 \%$, and $99.0 \%$, respectively, in $2 \mathrm{~h}$. Reaction constants of each compound were determined by fitting experimental data to the first order kinetic equation and the trial and error method with consecutive reaction pathway. As analysis results of reaction constants, UV with prepared photocatalyst was found to be effective and the decomposition of acetone was found to be the rate-determining step. The immobilized photocatalyst developed in this study would be useful for application of wastewater reuse with high removal efficiencies, mild preparation conditions, and mechanical stability.
\end{abstract}

Keywords: electronic wastewater; low-molecular-weight (LMW) compounds; photocatalytic media; sol-gel method

\section{Introduction}

According to a Korean government report, the most water-intensive sectors are textile, pulp, and electronics industries, and the water consumption in those industries has gradually increased over the years [1]. In particular, the electronics industry has undergone a severe water shortage problem due to its recent rapid growth and limited water supply. The production facilities in electronics industries, such as semiconductors and display manufacturing, use various toxic chemicals, mostly low molecular organic compounds, such as isopropyl alcohol and acetone [2]. These compounds are not completely removed by conventional wastewater treatment processes, such as reverse osmosis and biological treatment. To meet stringent water quality needs in the electronics industry, additional treatments, such as advanced oxidation processes (AOPs), have been considered [3]. AOPs utilize hydroxyl radicals with a greater oxidation potential than chemical oxidants for decomposing low molecular weight 
compounds. Service water, so-called ultrapure water, in the electronics industry requires high purity to avoid contamination of the products. To meet the required purity, tap water that is readily purified by several processes, is further treated with a complex combination of unit processes, such as reverse osmosis, ion exchange, and ultrafiltration. This combination of processes demands a large footprint and capital expense depending on the raw water quality and required purity. Thus, the following strategy for managing wastewater and its reuse stream has been considered. Once a waste stream consisting of low molecular weight organic compounds, e.g., rinsing water, is appropriately separated, it can be treated by a simple AOP-based process for reuse [4]. The development of efficient AOP technology has a great impact on the reuse of wastewater from the electronics industry.

There are many different methods used in AOPs, such as $\mathrm{UV}$, $\mathrm{UV}+\mathrm{O}_{3}, \mathrm{UV}+\mathrm{H}_{2} \mathrm{O}_{2}$, and $\mathrm{UV}+$ photocatalysts [5]. UV cannot completely degrade organic compounds into small molecules, such as water and carbon dioxide. $\mathrm{UV}+\mathrm{O}_{3}$ and $\mathrm{UV}+\mathrm{H}_{2} \mathrm{O}_{2}$ have disadvantages in the use of additional chemicals. Many studies have focused on the use of UV/photocatalysts due to strong photochemical activity and semi-permanent reusability without chemical addition. Photocatalysts are semiconducting metal oxides, such as $\mathrm{Al}_{2} \mathrm{O}_{3}, \mathrm{WO}_{3}, \mathrm{TiO}_{2}$, and $\mathrm{ZnO}$, which are able to produce hydroxyl radicals assisted by photons [6]. The most common photocatalyst is $\mathrm{TiO}_{2}$ due to its sufficient hydroxyl radical production capability and photo-chemical stability. There have been many studies on the immobilization of photocatalysts because it is not easy to recover small suspended photocatalyst particles for reuse [7]. Photocatalysts have been immobilized on supports, such as glass, sand, Teflon, activated carbon, and ceramics, by the sol-gel method, chemical vapor deposition, and physical vapor deposition [8]. Among these, the sol-gel method is a promising technique for immobilization of photocatalysts due to its mild conditions, simple process, and low cost [9].

The study on the removal of low molecular weight compounds by photocatalyst for reuse of electronics wastewater was relatively unexplored, while the development of an efficient AOP technology has a great impact on the expansion of the reuse process. In addition, it is challenging to immobilize photocatalysts in the sol-gel method with good morphology, photochemical activity, and mechanical stability due to many factors, such as concentration of the precursor, water to precursor ratio, $\mathrm{pH}$, aging time, and calcination conditions [10-12].

Authors suggested the immobilization of photocatalysts on hollow beads by chemical vapor deposition in the previous study for fluidized bed operation [13]. In this study, an extensive and systematic study was performed to optimize various factors in preparation conditions via efficient sol-gel routes to immobilize a photocatalyst on a hollow bead, as described in Scheme 1. In addition, the removal efficiencies of UV + prepared photocatalyst were compared with those of UV only. Furthermore, the reaction kinetics to describe experimental data were investigated and discussed.

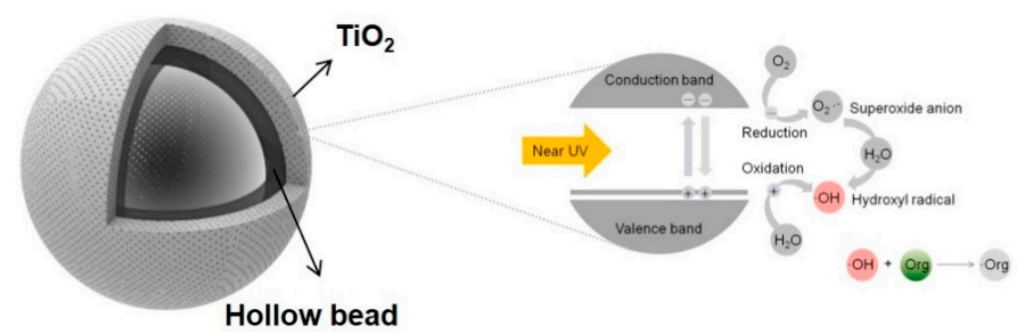

Scheme 1. Photocatalyst immobilized on a hollow bead for decomposition of low molecular weight pollutant in wastewater.

\section{Materials and Methods}

\subsection{Preparation and Characterization of Photocatalytic Media}

Ceramic hollow beads (DFL, Minmet Refractories Co, Cenosphere, China) were used as a support to bind photocatalysts in the fluidized bed reactor. These beads were mainly composed of alumina $\left(\mathrm{Al}_{2} \mathrm{O}_{3}\right)$ and silica $\left(\mathrm{SiO}_{2}\right)$ and were $40-300 \mu \mathrm{m}$ in diameter with particle density of $0.9-1.0 \mathrm{~g} / \mathrm{mL}$. 
Photocatalyst was immobilized in three steps. In the first step, the reactant and support were homogenized. Forty $\mathrm{ml}$ of methanol and nitric acid were mixed to adjust the $\mathrm{pH}$ of $1-7$. Various amounts of hollow beads (10-35 g) and titanium butoxide (4-16 mL) were mixed and stirred for $3 \mathrm{~min}$. The next step was the deposition of $\mathrm{a} \mathrm{TiO}_{2}$ layer on the support by hydrolysis and condensation reaction. Various amounts of distilled water $(0.6-3.6 \mathrm{~mL})$ were injected into the mixture with stirring for different aging times ranging from 0.5 to $2 \mathrm{~h}$. After completion of the reaction, unreacted reactants were decanted off and beads were retained by stainless steel mesh. After drying at the ambient temperature, beads were dried in the oven at $80{ }^{\circ} \mathrm{C}$ for $3 \mathrm{~h}$. The final step was building the crystalline structure of $\mathrm{TiO}_{2}$ on the surface of beads. The dried beads were calcined at different temperatures ranging from 400 to $800{ }^{\circ} \mathrm{C}$ for a calcination time of 1 to $4 \mathrm{~h}$. The preparation conditions of the photocatalytic media are listed in Table 1. The prepared photocatalytic media in different preparation conditions was analyzed using field emission scanning electron microscopy (FE-SEM, S-4800, Hitachi, Co., Japan) and an X-ray diffractometer (XRD, D/Max 2500 PC, Rigaku Co. Japan). FE-SEM specimens were attached to the sample holder using double sided carbon tape and subsequently coated by platinum before analysis. The X-ray emission angles ranged from 20 to 55 degrees with a $\mathrm{Cu}-\mathrm{k} \alpha$ source.

Table 1. Preparation conditions of photocatalyst by sol-gel method.

\begin{tabular}{|c|c|c|c|c|c|c|c|}
\hline \multirow{2}{*}{$\begin{array}{l}\text { No. of } \\
\text { Trials }\end{array}$} & \multicolumn{5}{|c|}{ Reaction } & \multicolumn{2}{|c|}{ Calcination } \\
\hline & $\begin{array}{l}\text { Amount of } \\
\text { Water (mL) }\end{array}$ & $\begin{array}{c}\text { Amount of } \\
\text { Precursor (mL) }\end{array}$ & $\begin{array}{c}\text { Aging Time } \\
\text { (min) }\end{array}$ & $\begin{array}{c}\text { Reaction } \\
\text { pH }\end{array}$ & $\begin{array}{l}\text { Amount of } \\
\text { Beads (g) }\end{array}$ & $\begin{array}{c}\text { Calcination } \\
\text { Temperature }\left({ }^{\circ} \mathrm{C}\right)\end{array}$ & $\begin{array}{c}\text { Calcination } \\
\text { Time (h) }\end{array}$ \\
\hline 1 & 0.6 & 12 & 60 & 1 & 20 & 500 & 2 \\
\hline 2 & 1.2 & 12 & 60 & 1 & 20 & 500 & 2 \\
\hline 3 & 2.4 & 12 & 60 & 1 & 20 & 500 & 2 \\
\hline 4 & 3.6 & 12 & 60 & 1 & 20 & 500 & 2 \\
\hline 5 & 2.4 & 4 & 60 & 1 & 20 & 500 & 2 \\
\hline 6 & 2.4 & 8 & 60 & 1 & 20 & 500 & 2 \\
\hline 7 & 2.4 & 16 & 60 & 1 & 20 & 500 & 2 \\
\hline 8 & 2.4 & 12 & 30 & 1 & 20 & 500 & 2 \\
\hline 9 & 2.4 & 12 & 90 & 1 & 20 & 500 & 2 \\
\hline 10 & 2.4 & 12 & 120 & 1 & 20 & 500 & 2 \\
\hline 11 & 2.4 & 12 & 60 & 3 & 20 & 500 & 2 \\
\hline 12 & 2.4 & 12 & 60 & 5 & 20 & 500 & 2 \\
\hline 13 & 2.4 & 12 & 60 & 7 & 20 & 500 & 2 \\
\hline 14 & 2.4 & 12 & 60 & 1 & 10 & 500 & 2 \\
\hline 15 & 2.4 & 12 & 60 & 1 & 15 & 500 & 2 \\
\hline 16 & 2.4 & 12 & 60 & 1 & 25 & 500 & 2 \\
\hline 17 & 2.4 & 12 & 60 & 1 & 30 & 500 & 2 \\
\hline 18 & 2.4 & 12 & 60 & 1 & 35 & 500 & 2 \\
\hline 19 & 2.4 & 12 & 60 & 1 & 15 & 400 & 2 \\
\hline 20 & 2.4 & 12 & 60 & 1 & 15 & 600 & 2 \\
\hline 21 & 2.4 & 12 & 60 & 1 & 15 & 700 & 2 \\
\hline 22 & 2.4 & 12 & 60 & 1 & 15 & 800 & 2 \\
\hline 23 & 2.4 & 12 & 60 & 1 & 15 & 500 & 1 \\
\hline 24 & 2.4 & 12 & 60 & 1 & 15 & 500 & 3 \\
\hline 25 & 2.4 & 12 & 60 & 1 & 15 & 500 & 4 \\
\hline
\end{tabular}

\subsection{Evaluation of Removal Efficiencies of Target Compounds}

As described in Figure 1, a modified drying oven $\left(900 \times 900 \times 900 \mathrm{~mm}^{3}\right.$ in size $)$ was used as an experimental apparatus for photocatalytic activity of prepared media. A quartz dish that was $160 \mathrm{~mm}$ in diameter and $50 \mathrm{~mm}$ in height was used as a reaction vessel to hold $1 \mathrm{~L}$ of synthetic wastewater and $1.125 \mathrm{~g}$ of photocatalytic media. A UV lamp (Atlantic Ultraviolet, GPH357T5L-17W, USA) was installed on top of the oven for irradiation of the photocatalyst. The distance between the UV lamp and reaction vessel was $50 \mathrm{~mm}$. Synthetic wastewater was prepared to simulate wastewater for reuse in the electronics industry by using $1000 \mu \mathrm{g} / \mathrm{L}$ of spiking isopropyl alcohol, acetone, ethanol, and acetaldehyde. In addition, a removal experiment with UV irradiation was performed for comparison. The concentrations of target compounds were adjusted to $1000 \mu \mathrm{g} / \mathrm{L}$. Samples from the reaction vessel were taken with time and the concentrations of target compounds were quantified using gas chromatography with mass spectroscopy (GC/MS, gas chromatography 7820A, mass spectrometry 5975, Agilent) coupled with purge and trap (Stratum, Teledyne, Tekmar, USA). The operational conditions of purge and trap were as follows. Sample and purge temperatures 
were $40{ }^{\circ} \mathrm{C}$. Nitrogen gas was used for purging with a flow rate of $100 \mathrm{~mL} / \mathrm{min}$ for $8 \mathrm{~min}$. The following conditions were used for GC-MS analysis. The target compounds in the sample were separated with a DB-624 column (Agilent). The temperatures of the inlet and detector were $100{ }^{\circ} \mathrm{C}$ and $250{ }^{\circ} \mathrm{C}$, respectively. The oven temperature was held at $35^{\circ} \mathrm{C}$ for $7 \mathrm{~min}$ and $46^{\circ} \mathrm{C}$ for $5 \mathrm{~min}$ with a ramping rate of $3{ }^{\circ} \mathrm{C} / \mathrm{min}$. Standard solutions for target compounds were prepared by series dilution of stock solution prepared by American Chemical Society (ACS) grade chemicals (Sigma Aldrich). Deviation from calibration curve was checked in every 3-5 samples and kept less than $10 \%$. The concentrations of target compounds in the blank eluent from hollow beads, dissolved in water from air, and in distilled water were measured to correct the baseline as described in the literature [13].

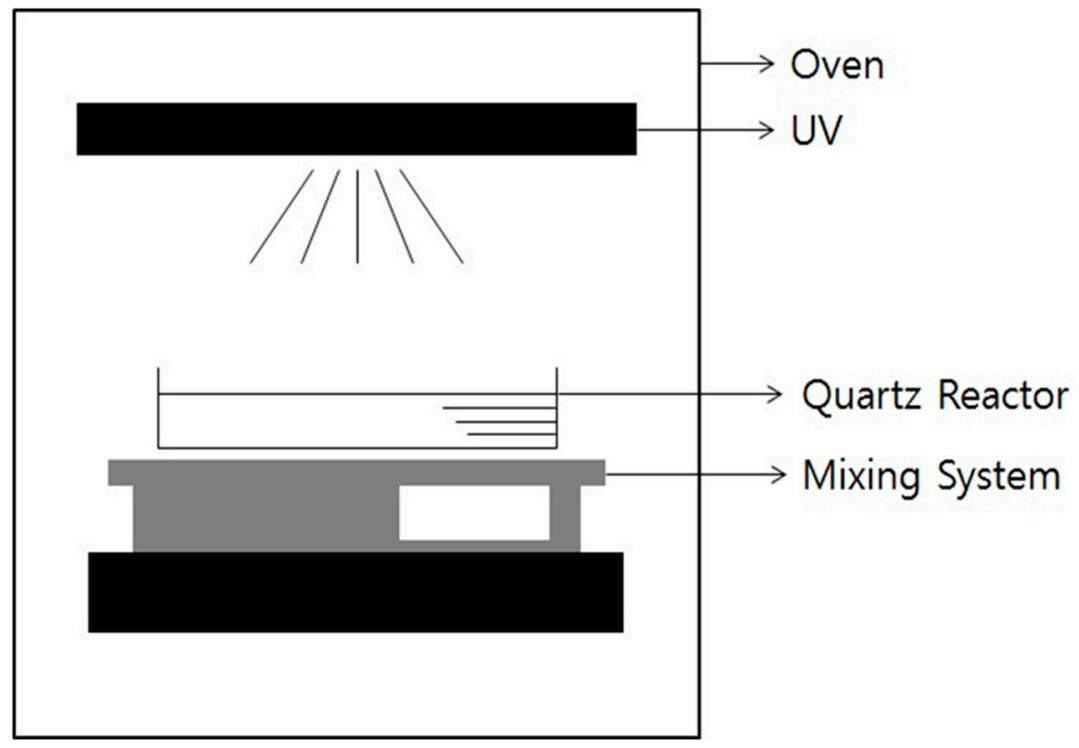

Figure 1. Test equipment for immobilized photocatalyst.

\section{Results and Discussion}

\subsection{Preparation and Characterization of Photocatalysts}

Immobilized photocatalysts under various conditions were prepared and removal efficiencies of a single constituent (isopropyl alcohol, as a representative for target compounds) were evaluated for selection of preparation conditions. These preliminary tests were conducted in high loading conditions (10 mg/L of isopropyl alcohol) to amplify sensitivity of removal in different preparation conditions with a single constituent rather than testing with multiple constituents ( $1 \mathrm{mg} / \mathrm{L}$ of each). The removals of isopropyl alcohol in various preparation conditions are presented in Figure $2 \mathrm{a}-\mathrm{f}$. Supportive SEM images and XRD patterns are presented in Figures 3 and 4, respectively.

Figure $2 \mathrm{a}$ indicates that a decrease in the amount of support with a fixed amount of precursor led to higher removal possibly due to the increase in active sites of the support for anchoring more precursors. In Figure $2 b$, an increase in the amount of precursor with a fixed amount of support tends to raise the amount of removal due to the formation of a thicker coating layer (data not shown). As shown in Figure 2c, the removal increased with aging time and reached a maximum at $60 \mathrm{~min}$. A defective layer of photocatalyst is shown in Figure $3 b$ (aging time $=120 \mathrm{~min}$ ), while a defect-less layer is shown in Figure $3 a$ (aging time $=60 \mathrm{~min}$ ). The detachment of the excessive coating layer was observed after calcination of photocatalyst with more than $60 \mathrm{~min}$ of aging time. Thus, the 60 min was chosen as an optimal aging time with maximal thickness of 100-150 nm (measured in SEM analysis). The amount of precursor, support, and aging time were variables affecting the mechanical stability as well as photochemical ability of photocatalyst. 

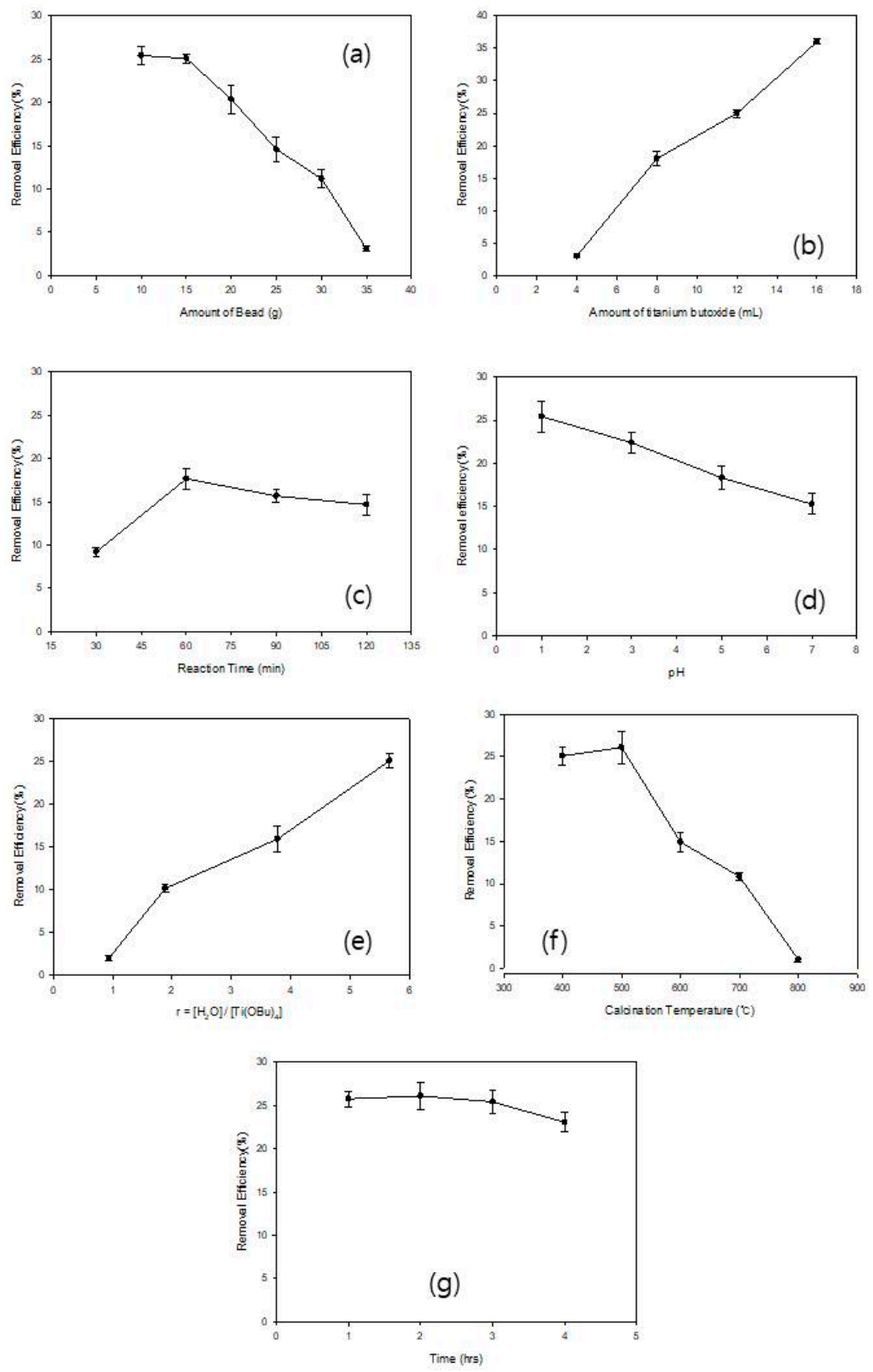

Figure 2. Effects of (a) amount of support, (b) amount of precursor, (c) aging time, (d) $\mathrm{pH}$, (e) amount of water, (f) calcination temperature, and ( $g$ ) calcination time in preparation of immobilized photocatalyst on the removal efficiency of isopropyl alcohol (tested under synthetic wastewater initial concentration of $10 \mathrm{mg} / \mathrm{L})$. 

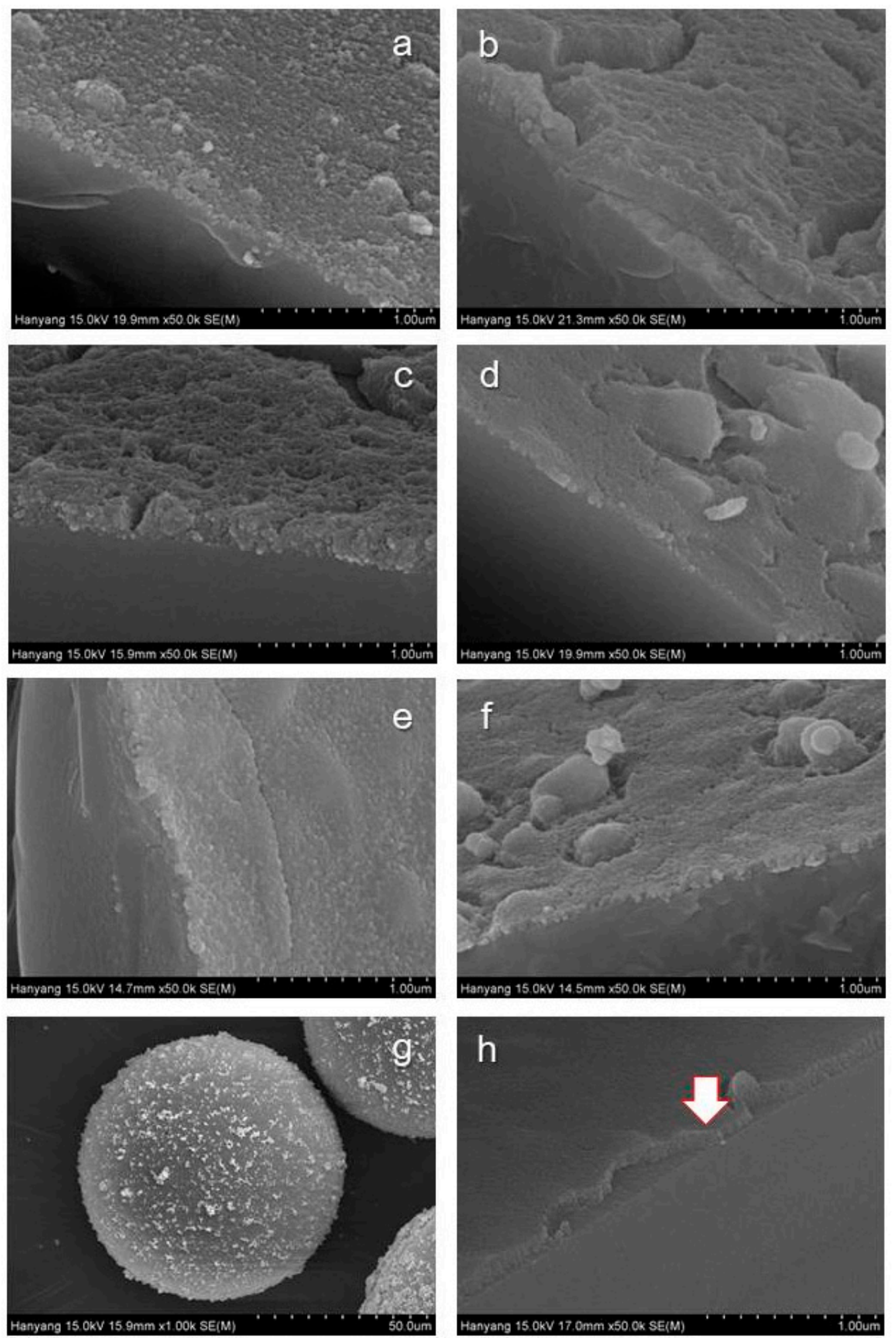

Figure 3. Surface morphologies of photocatalytic media prepared under different conditions: (a) Aging time $=60 \mathrm{~min},(\mathbf{b})$ aging time $=120 \mathrm{~min},(\mathbf{c}) \mathrm{pH}=1,(\mathbf{d}) \mathrm{pH}=7,(\mathbf{e})$ amount of water $=0.6 \mathrm{~mL},(\mathbf{f})$ amount of water $=3.6 \mathrm{~mL}$, and those prepared in optimized conditions in different magnifications $(\mathbf{g})$ and $(\mathbf{h})$, arrow for deposition of photocatalyst layer in (h). 

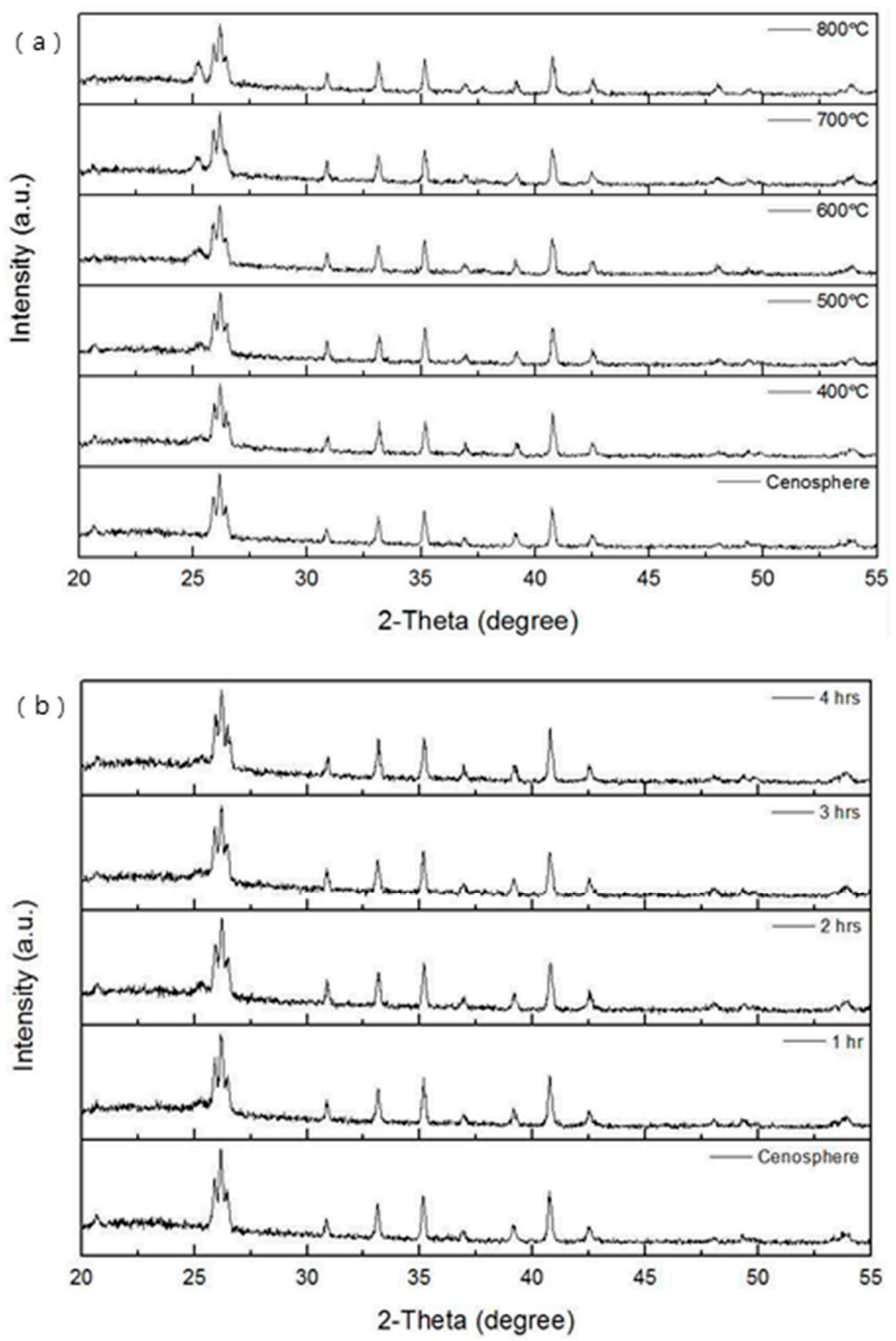

Figure 4. Phase structures of photocatalytic media under different conditions: (a) Calcination temperatures, and $(\mathbf{b})$ calcination times (prepared in the optimized reaction conditions (amount of water $=2.4 \mathrm{~mL}$, amount of precursor $=12 \mathrm{~mL}$, aging time $=60 \mathrm{~min}$, reaction $\mathrm{pH}=1$, amount of beads $=15 \mathrm{~g})$ ).

In addition, the $\mathrm{pH}$ and amount of water in the sol-gel reaction plays an important role in controlling the reaction rate of hydrolysis and condensation [14]. Figure 2d,e indicate that a lower $\mathrm{pH}$ and more water addition favor a higher removal. The SEM results in Figure $3 \mathrm{~d}, \mathrm{f}$ show that a high $\mathrm{pH}$ and more water addition produced agglomeration on the surface of the photocatalyst layer. The water to precursor molar ratio $\left(\mathrm{r}=\left[\mathrm{H}_{2} \mathrm{O}\right] /\left[\mathrm{Ti}(\mathrm{OBu})_{4}\right]\right)$ in the sol-gel process strongly affected the morphology of the photocatalyst. It was reported that the $\mathrm{Ti}(\mathrm{OBu})_{4}$ precursor was fully hydrolyzed to $\mathrm{Ti}(\mathrm{OOH})_{4}$ in a high ratio $(r=4)$, while it was partially hydrolyzed to $\operatorname{Ti}(\mathrm{OH})_{\mathrm{r}}(\mathrm{OBu})_{4 \text {-r }}$ in a low $\mathrm{r}$ ratio $(\mathrm{r}<4)$. The fully hydrolyzed precursor would lead to a more crosslinked structure [15]. In addition, it has 
been reported that a high $\mathrm{r}$ ratio favored a smaller size of particles, which is in agreement with the results of this study [11]. Amount of water was determined to have $\mathrm{r}$ close to 4 (amount of water = $2.4 \mathrm{~mL}$ ) with less agglomeration.

In the literature, the anatase phase was easily developed at a $\mathrm{pH}$ above 4.5 , while the rutile phase was at a lower $\mathrm{pH}$ between 2.5-4.5 [16]. However, it was noted that the anatase phase could be formed at a low $\mathrm{pH}$ and low calcination temperature in another report [17]. In addition, it was claimed that a low $\mathrm{pH}$ (about 2) led to a small spherical nano-sized particle, while a higher $\mathrm{pH}$ led to bigger particles [11]. The plausible explanation for this result was that the positively charged surface of the support and precursor in a low $\mathrm{pH}$ exhibited a repulsive force reducing the reaction rate of the precursor. This relatively slow reaction rate in a lower $\mathrm{pH}$ would result in a uniform surface with smaller grain than the discrete surface in a higher $\mathrm{pH}$. This was in agreement with the formation of agglomerations at a higher $\mathrm{pH}$ in this study and in the literature [12]. The preparation conditions of the sol-gel process (amount of support $=15 \mathrm{~g}$, amount of precursor $=12 \mathrm{~mL}$, amount of water $=2.4 \mathrm{~mL}$, and aging time $=60 \mathrm{~min}$ ) were chosen accordingly based on the experimental investigations.

Calcination conditions significantly affected the crystalline structure of the photocatalyst. The removal tended to decrease with an increase in sintering temperature from 500 to $800{ }^{\circ} \mathrm{C}$, as shown in Figure 2f. Calcination time does not significantly change after $2 \mathrm{~h}$, as shown in Figure $2 \mathrm{~g}$. The XRD patterns shown in Figure $4 \mathrm{a}$ indicate that the intensity peak $\left(25^{\circ}\right)$ of the anatase phase appeared at sintering temperatures of $500-700^{\circ} \mathrm{C}$, while those of the rutile phase peak $\left(37.5^{\circ}\right)$ appeared at $800^{\circ} \mathrm{C}$. In Figure $4 \mathrm{~b}$, the anatase phase peak appeared after $2 \mathrm{~h}$ of calcination. The higher removal in low calcination temperatures $\left(450-500{ }^{\circ} \mathrm{C}\right)$ was due to the formation of the anatase phase with a higher purity. This calcination temperature was close to that in the literature $\left(350-450^{\circ} \mathrm{C}\right)$ where the anatase phase could be fully developed from the amorphous phase [10]. The calcination conditions were determined to have a high removal efficiency (calcination temperature $=500^{\circ} \mathrm{C}$ and calcination time $=$ $2 \mathrm{~h}$ ). SEM images of immobilized photocatalyst are shown in Figure 3g,h with different magnifications. A uniform and smooth surface of the photocatalyst was successfully developed on the surface of media. The diameter of the prepared media was about $100 \mu \mathrm{m}$ and the thickness of deposition layer was about $100 \mathrm{~nm}$.

\subsection{UV/Photocatalytic Removal and Reaction Kinetics}

Removal efficiencies of target compounds with immobilized photocatalyst under UV irradiation are presented in Figure $5 \mathrm{a}-\mathrm{d}$. In addition, experimental removal efficiencies without photocatalysts (UV only) were included in the figures for comparison. The removal efficiencies of isopropyl alcohol, ethanol, and acetaldehyde with immobilized photocatalyst are clearly higher than those without photocatalysts at all times. However, the removal efficiencies of acetone by photocatalytic media were lower than those with UV only from 15 to $60 \mathrm{~min}$, while they were higher at $120 \mathrm{~min}$. To account for this discrepancy, reaction kinetics were calculated and compared. After trials of fitting experimental data to the rate equations from zero to second order kinetics, the first-order kinetics were determined as follows:

$$
\begin{aligned}
\frac{d C_{i}}{d t} & =-k_{i, a p} C_{i} \\
\frac{C_{i}}{C_{i 0}} & =e^{-k_{i, a p} t}
\end{aligned}
$$

where $i=a, b, c, d$ ( $a$ : isopropyl alcohol, $b$ : acetone, $c$ : ethanol, and $d$ : acetaldehyde); and $k_{i}$ is the apparent reaction constant of the $i$ compound. 

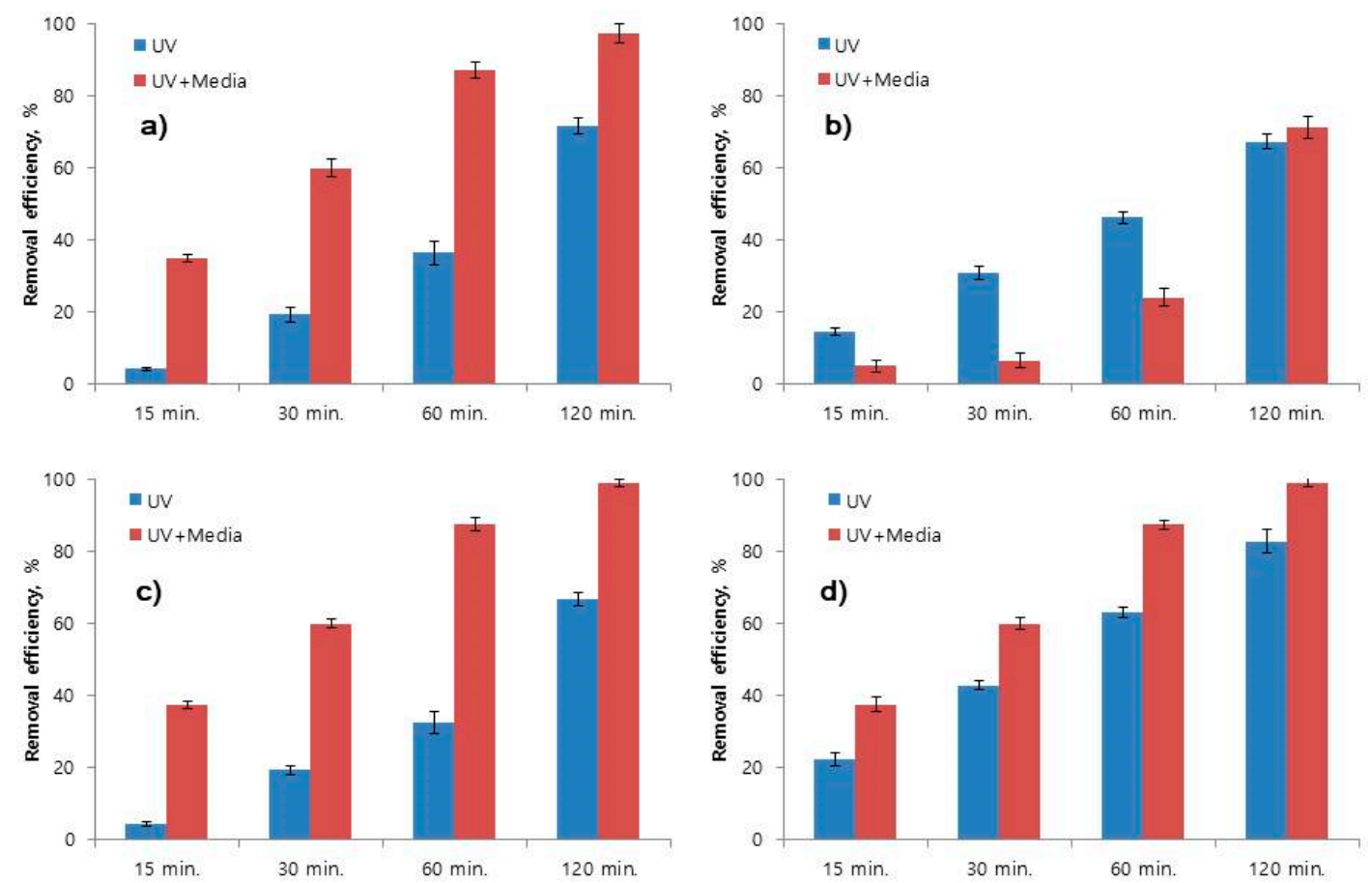

Figure 5. Removal efficiencies of (a) isopropyl alcohol, (b) acetone, (c) ethanol, and (d) acetaldehyde by UV and UV + prepared photocatalyst. (Tested under synthetic wastewater with $1 \mathrm{mg} / \mathrm{L}$ of isopropyl alcohol, acetone, ethanol, and acetaldehyde, respectively).

The apparent reaction constants of target compounds are calculated and are listed in Table 2. The reaction constants of isopropyl alcohol and ethanol were determined with a high coefficient of determination $\left(R^{2}=0.99\right)$, while those of acetone and acetaldehyde were determined with a poor to moderate coefficient of determination $\left(R^{2}=0.91-0.97\right)$. The possible reasons for this poor correlation could have originated from the formation of byproducts. Thus, the consecutive reaction relationships of isopropyl alcohol, acetone, ethanol, and acetaldehyde were considered as shown in Figure 6 [18-21].

Table 2. Reaction constants of target compounds for decomposition by UV and UV + photocatalytic media.

\begin{tabular}{ccccc}
\hline Reaction Constants & \multicolumn{2}{c}{ UV } & \multicolumn{2}{c}{ UV + Photocatalytic Media } \\
\hline$k_{a}$ & 0.0092 & $\left(\mathrm{R}^{2}=0.99\right)$ & 0.0303 & $\left(\mathrm{R}^{2}=0.99\right)$ \\
$k_{b, a p,}$ & 0.0097 & $\left(\mathrm{R}^{2}=0.96\right)$ & 0.0106 & $\left(\mathrm{R}^{2}=0.91\right)$ \\
$k_{b, c o}$ & 0.0200 & $\left(\mathrm{R}^{2}=0.99\right)$ & 0.0200 & $\left(\mathrm{R}^{2}=0.96\right)$ \\
$k_{c}$ & 0.0093 & $\left(\mathrm{R}^{2}=0.99\right)$ & 0.0387 & $\left(\mathrm{R}^{2}=0.99\right)$ \\
$k_{d, a p}$ & 0.0145 & $\left(\mathrm{R}^{2}=0.97\right)$ & 0.0386 & $\left(\mathrm{R}^{2}=0.97\right)$ \\
$k_{d, c o}$ & 0.0500 & $\left(\mathrm{R}^{2}=0.99\right)$ & 0.0950 & $\left(\mathrm{R}^{2}=0.98\right)$ \\
\hline
\end{tabular}

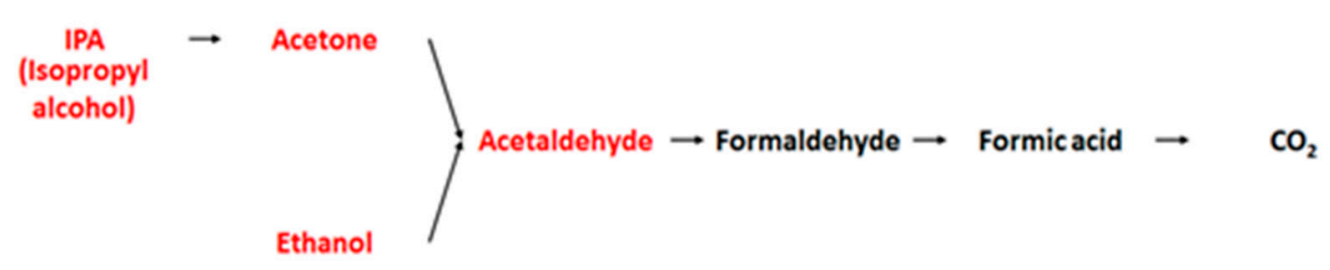

Figure 6. Reaction pathway and relationships of consecutive reaction. 
The reactions between target compounds and hydroxyl radicals involved in the reaction pathway would be described as follows:

$$
\begin{gathered}
\operatorname{IPA}\left(\mathrm{C}_{3} \mathrm{H}_{8} \mathrm{O}\right)+2 \cdot \mathrm{OH} \rightarrow \text { Acetone }\left(\mathrm{C}_{3} \mathrm{H}_{6} \mathrm{O}\right)+2 \mathrm{H}_{2} \mathrm{O} \\
\text { Ethanol }\left(\mathrm{C}_{2} \mathrm{H}_{6} \mathrm{O}\right)+2 \cdot \mathrm{OH} \rightarrow \text { Acetaldehyde }\left(\mathrm{C}_{2} \mathrm{H}_{4} \mathrm{O}\right)+2 \mathrm{H}_{2} \mathrm{O} \\
\text { 2Acetone }\left(\mathrm{C}_{3} \mathrm{H}_{6} \mathrm{O}\right)+2 \cdot \mathrm{OH} \rightarrow 3 \text { Acetaldehyde }\left(\mathrm{C}_{2} \mathrm{H}_{4} \mathrm{O}\right)+\mathrm{H}_{2} \mathrm{O}
\end{gathered}
$$

According to this reaction pathway, isopropyl alcohol decomposes to acetone, which decomposes to acetaldehyde. In addition, ethanol decomposes to acetaldehyde. Acetone and aldehyde are not only decomposed, but they are also produced during UV photolysis with or without a photocatalyst. When the first-order kinetics and the suggested reaction pathway are assumed, the rate equations are as follows:

$$
\begin{aligned}
& \frac{d C_{a}}{d t}=-k_{a, a p} C_{a} \\
& \frac{C_{a}}{C_{a 0}}=e^{-k_{a, a p} t} \\
& \frac{d C_{b}}{d t}=k_{a, a p} C_{a}-k_{b, c o} C_{b} \\
& \frac{C_{b}}{C_{b 0}}=e^{-k_{b, c o} t}+\frac{k_{a}}{k_{b}-k_{a}}\left(e^{-k_{a, a p} t}-e^{-k_{b, c o} t}\right) \\
& \frac{d C_{c}}{d t}=-k_{c, a p} C_{c} \\
& \frac{C_{c}}{C_{c 0}}=e^{-k_{c, a p} t} \\
& \frac{d C_{d}}{d t}=k_{b, c o} C_{b}+k_{c, a p} C_{c}-k_{b, c o} C_{d} \\
& \frac{C_{d}}{C_{d 0}}=e^{-k_{d, c o} t}+\frac{k_{b, c o}}{\left(k_{d, c o}-k_{b, c o}\right)}\left(e^{-k_{b, c o} t}-e^{-k_{d, c o} t}\right)+\frac{k_{c, a p}}{\left(k_{d, c o}-k_{c, a p}\right)}\left(e^{-k_{c, a p} t}-e^{-k_{d, c o} t}\right) \\
& +\frac{k_{a, a p} k_{b, c o}}{\left(k_{b, c o}-k_{a, a p}\right)}\left(\frac{e^{-k_{a, a p t}}-e^{-k_{d, c o t}}}{k_{d, c o}-k_{a, a p}}-\frac{e^{-k_{b, c o}}-e^{-k_{d, c o t}}}{k_{d, c o}-k_{b, c o}}\right)
\end{aligned}
$$

Here, the subscript a is isopropyl alcohol, $\mathrm{b}$ is acetone, $\mathrm{c}$ is ethanol, and $\mathrm{d}$ is acetaldehyde;

$k_{i, a p}$ is the apparent reaction constant; and $k_{i, c o}$ is the reaction constant with the consecutive reaction relationship.

$k_{b, c o}$ and $k_{b, c o}$ were determined to have high coefficients of determination $\left(\mathrm{R}^{2}\right)$ using the trial and error method with equations for $C_{b}$ and $C_{d}$ t. This coefficient was calculated using the following equations:

$$
\begin{aligned}
\mathrm{SS}_{\text {res }} & =\sum_{i}\left(y_{i}-f_{i}\right)^{2} \\
\mathrm{SS}_{\text {tot }} & =\sum_{i}\left(y_{i}-\bar{y}\right)^{2} \\
\mathrm{R}^{2} & =\frac{\mathrm{SS}_{\text {res }}}{S S_{\text {tot }}}
\end{aligned}
$$

where, $y_{i}$ are experimental data and $f_{i}$ are calculated values.

The newly calculated reaction constants are listed in Table 2, which are used to describe experimental data under UV irradiation with and without photocatalysts, as shown in Figure 7. When the newly calculated reaction constants are used, the experimental data is described better with a higher coefficient of determination, as shown in Figure 7. This type of approach would be useful when apparent reaction constants are determined with a poor coefficient of determination. UV with 
prepared photocatalyst was found to be effective, because its reaction constants were higher than those without photocatalysts with a fairly good coefficient of determination. In addition, it was revealed that the UV irradiation with and without prepared media mostly followed the suggested reaction pathway with a consecutive relationship. The low removal efficiency of acetone in 15-60 min was caused by a consecutive reaction relationship, and the difference in reaction constants between isopropyl alcohol and acetone. If decomposition of acetone was fast like that of acetaldehyde, the reduced decomposition rate would not occur. The decomposition of acetone was found to be a rate-determining step in the overall reaction with $\mathrm{UV} /$ photocatalyst. The optimization of preparation conditions with acetone removal instead of isopropyl alcohol would be a challenging, but valuable, approach.
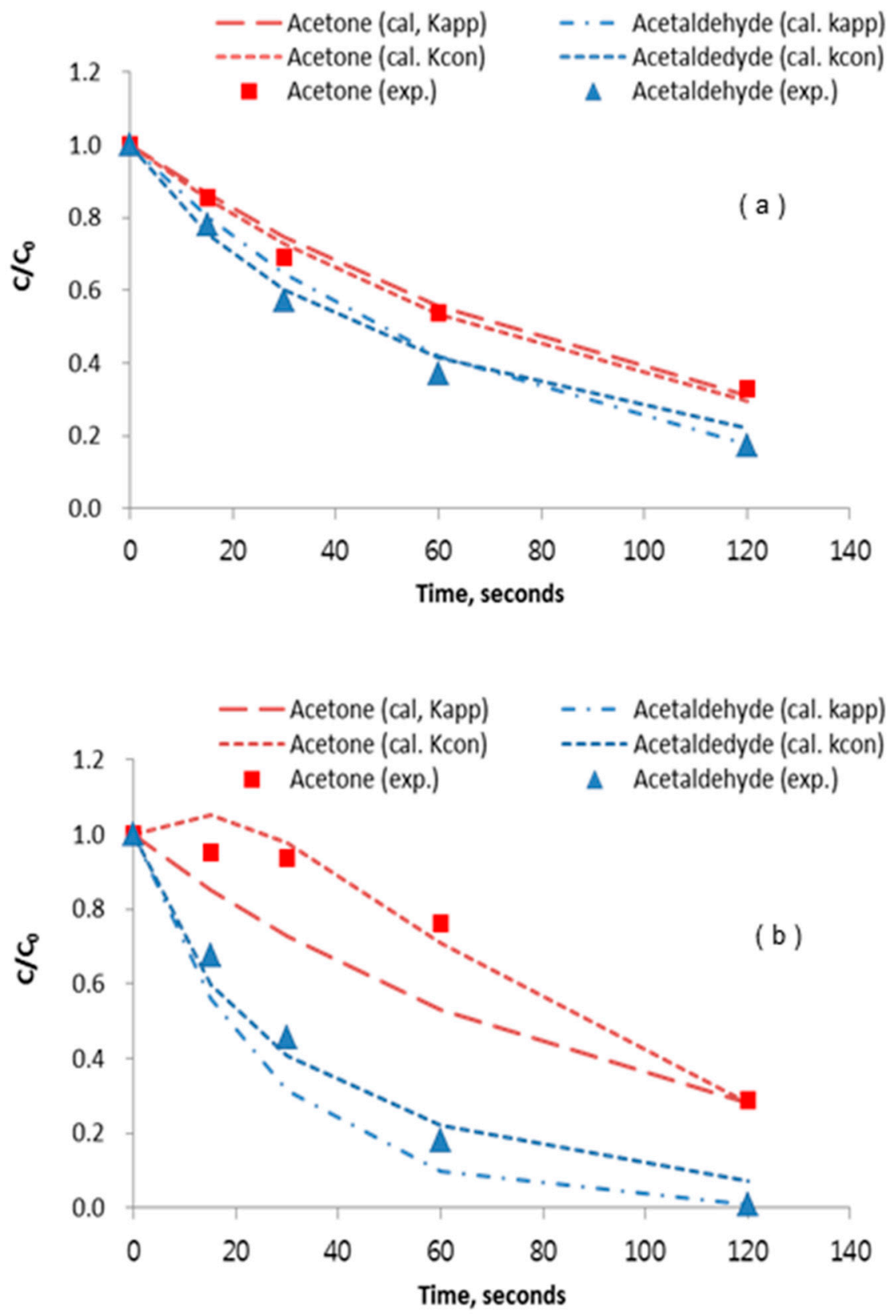

Figure 7. Experimental and calculated values (using $K_{a p p}$ and $K_{c o n}$ ) of acetone and acetaldehyde by (a) UV, and (b) UV + photocatalytic media. 


\section{Conclusions}

A photocatalyst was immobilized using the sol-gel based method for decomposing low molecular weight compounds in electronics wastewater for reuse. The amount of precursor and support, water to precursor ratio, $\mathrm{pH}$, aging time, and calcination conditions were optimized by removal of isopropyl alcohol as a representative of target compounds. SEM and XRD analysis results were performed for aiding selection of variables. The preparation conditions of the sol-gel process (amount of support $=15 \mathrm{~g}$, amount of precursor $=12 \mathrm{~mL}$, amount of water $=2.4 \mathrm{~mL}$, and aging time $=60 \mathrm{~min}$ ) and the subsequent calcination conditions (calcination temperature $=500{ }^{\circ} \mathrm{C}$ and calcination time $=2 \mathrm{~h}$ ) were determined to have a high removal efficiency of isopropyl alcohol. Removal efficiencies of isopropyl alcohol, acetone, ethanol, and acetaldehyde in synthetic wastewater with UV irradiation and photocatalyst reached $97.2 \%, 71.2 \%, 99.0 \%$, and $99.0 \%$ in $2 \mathrm{~h}$. To better understand the mechanism of photocatalytic decomposition of low molecular weight compounds, the reaction kinetics of the target compound were investigated. Reaction constants were determined by fitting experimental data and the trial and error method with the assumption of first order kinetics with consecutive reaction pathway. The suggested reaction pathway was confirmed and UV with prepared photocatalysts was found effective after comparison of the reaction constants. The decomposition of acetone was found to be a rate-determining step in the overall reaction by UV/photocatalyst. The prepared photocatalysts have great potential in the application of wastewater reuse by decomposition of low molecular weight organic compounds.

Author Contributions: J.C. (Conceptualization, Writing-original draft), S.C. (Data curation, Investigation), G.L. (Methodology, Visualization), Y.-W.L. (Data curation, Writing-review\&editing). All authors have read and agreed to the published version of the manuscript.

Funding: This research was supported by a grant (No. 405-111-004) from Eco-Innovation project funded by Ministry of Environment, Korea.

Conflicts of Interest: The authors declare no conflicts of interest

\section{References}

1. Korean Ministry of Environment (KME). Industrial Waste Water Generation and Treatment; Korean Ministry of Environment: Sejong City, Korea, 2017.

2. Reinhardt, K.; Kern, W. Handbook of Silicon Wafer Cleaning Technology, 2nd ed.; Elsevier Science: Amsterdam, The Netherlands, 2008.

3. Choi, J.; Chung, J. Evaluation of potential for reuse of industrial wastewater using metal-immobilized catalysts and reverse osmosis. Chemosphere 2015, 125, 139-146. [CrossRef] [PubMed]

4. Choi, J.; Kim, J.; Chung, J. Removal of isopropyl alcohol and methanol in ultrapure water production system using a $185 \mathrm{~nm}$ ultraviolet and ion exchange system. Chemosphere 2016, 156, 341-346. [CrossRef] [PubMed]

5. Andreozzi, R.; Caprio, V.; Insola, A.; Marotta, R. Advanced oxidation processes (AOP) for water purification and recovery. Catal. Today 1999, 53, 51-59. [CrossRef]

6. Osterloh, F.E. Inorganic materials as catalysts for photochemical splitting of water. Chem. Mater. 2008, 20, 35-54. [CrossRef]

7. Matthews, R.W. Photooxidative degradation of coloured organics in water using supported catalysts. $\mathrm{TiO}_{2}$ on sand. Water Res. 1991, 25, 1169-1176. [CrossRef]

8. Bideau, M.; Claudel, B.; Dubien, C.; Faure, L.; Kazouan, H. On the "immobilization" of titanium dioxide in the photocatalytic oxidation of spent waters. J. Photochem. Photobiol. 1995, 91, 137-144. [CrossRef]

9. Kumar, K.N.P.; Keizer, K.; Burggraaf, A. Densification of nanostructured titania assisted by a phase transformation. Nature 1992, 358, 48-51. [CrossRef]

10. Bessekhouad, Y.; Robert, D.; Weber, J.V. Preparation of $\mathrm{TiO}_{2}$ nanoparticles by Sol-Gel route. Int. J. Photoenergy 2003, 5, 153-158. [CrossRef]

11. Mashshid, S.; Askari, M.; Ghamsari, M.S. Synthesis of $\mathrm{TiO}_{2}$ nanoparticles by hydrolysis and peptization of titanium isopropoxide solution. J. Mater. Process. Technol. 2007, 189, 296-300. [CrossRef] 
12. Fajriati, I.; Mudasir, M.; Wahyuni, E.T. The effect of $\mathrm{pH}$ and aging time on the synthesis of $\mathrm{TiO}_{2}-\mathrm{Chitosan}$ nanocomposites as photocatalyst by sol-gel method at room temperature. Molekul 2017, 12, 117-125. [CrossRef]

13. Chung, S.; Chung, J.; Lee, Y. Use of TiO2 Media by Sputtering and Peroxy Gel Method for Wastewater Reuse in the Electronics Industry. Sci. Adv. Mat. 2019, 11, 1547-1555. [CrossRef]

14. Marchisio, D.L.; Omegna, F.; Barresi, A.A.; Bowen, P. Effect of mixing and other operating parameters in sol-gel processes. Ind. Eng. Chem. Res. 2008, 47, 7202-7210. [CrossRef]

15. Ding, X.; Qi, Z.; He, Y. Effect of hydrolysis water on the preparation of nano-crystalline titania powders via a sol-gel process. J. Mater. Sci. Lett. 1995, 14, 21-22. [CrossRef]

16. Cassaignon, S.; Koelsch, M.; Jolivet, J.P. From $\mathrm{TiCl}_{3}$ to $\mathrm{TiO}_{2}$ nanoparticles (anatase, brookite and rutile): Thermohydrolysis and oxidation in aqueous medium. Phys. Chem. Solids 2007, 68, 695-700. [CrossRef]

17. Tsega, M.; Dejene, F.B. Influence of acidic $\mathrm{pH}$ on the formulation of $\mathrm{TiO}_{2}$ nanocrystalline powders with enhanced photoluminescence property. Heliyon 2017, 3, e00246. [CrossRef] [PubMed]

18. Addamo, M.; Augugliaro, V.; Coluccia, S.; Faga, M.G.; García-López, E.; Loddo, V.; Marcì, G.; Martra, G.; Palmisano, L. Photocatalytic oxidation of acetonitrile in gas-solid and liquid-solid regimes. J. Catal. 2005, 235, 209-220. [CrossRef]

19. Arsac, F.; Bianchi, D.; Chovelon, J.M.; Ferronato, C.; Herrmann, J.M. Experimental microkinetic approach of the photocatalytic oxidation of isopropyl alcohol on $\mathrm{TiO}_{2}$. Part 1. surface elementary steps involving gaseous and adsorbed $\mathrm{C}_{3} \mathrm{H}_{\mathrm{x}} \mathrm{O}$ species. J. Phys. Chem. A 2006, 110, 4202-4212. [CrossRef] [PubMed]

20. Muggli, D.S.; McCue, J.T.; Falconer, J.L. Mechanism of the photocatalytic oxidation of ethanol on $\mathrm{TiO}_{2}$. J. Catal. 1998, 173, 470-483. [CrossRef]

21. Ye, X.; Chen, D.; Gossage, J.; Li, K. Photocatalytic oxidation of aldehydes: Byproduct identification and reaction pathway. J. Photochem. Photobiol. 2006, 183, 35-40. [CrossRef]

(C) 2020 by the authors. Licensee MDPI, Basel, Switzerland. This article is an open access article distributed under the terms and conditions of the Creative Commons Attribution (CC BY) license (http://creativecommons.org/licenses/by/4.0/). 